\title{
The Matching Research on Carrying Capacity of Shenyang Dalian Highway and Development of High-tech Industry Belt in Central and Southern Liaoning Province
}

\author{
Hua Zou ${ }^{1}$ and Shiqi Wang ${ }^{1 *}$ \\ ${ }^{1}$ School of Management, Shenyang University of Technology, Shenyang, 110870, \\ China \\ ${ }^{1}$ Email:872085971@qq.com
}

\begin{abstract}
This paper uses time series prediction and linear regression model to forecast respectively the carrying capacity of Shenyang Dalian highway and the freight demand of high-tech industry belt in central and southern Liaoning province from 2016 to 2020, then analyzes their matching condition, finally, drawing a conclusion that the carrying capacity of Shenyang Dalian highway is more than the freight demand for the development of high-tech industry belt in central and southern Liaoning province.
\end{abstract}

Keywords: Shenyang Dalian Highway; Central and southern Liaoning province; High-tech industry belt; Forecast; Matching

\section{Introduction}

Shenyang Dalian highway has powerful carrying capacity, so Shenyang, Dalian, Anshan, Liaoyang and Yingkou have successively developed national high-tech industry zones depending on its obvious advantage. Due to the spread influence of Shenyang Dalian highway, Benxi has become a city with national high-tech industry zone, and the six national high-tech industry zones and provincial industry zones surrounding them constitute high-tech industry belt in central and southern Liaoning province.

At present, as for highway industry, the researches mainly focus on development condition and border demarcation method of industry belt. Wu Donghao [1] expressed early the formation infrastructure and conditions of industry belt along the highway, and took Jingjintang highway in Beijing section as an example to introduce the gradient function partition method. Li Haidong [2] combined theory and practice, summarized the development stage of highway industry belt in china, and proposed the development goals of highway industry. Niu Junke [3] respectively used gradient function partition method, calculation method, geometric method, and analysis of mathematical methods to divide the industry belt boundary, and proposed the adapt condition of these methods. Besides, some scholars studied Shenyang Dalian high-tech industry belt, for example, Zhou Wenjuan [4] defined the scope of the Shenyang Dalian economic belt and summarized its characteristics. Zhou Ren [5] analyzed the development stage of high-tech industry in Liaoning province, and summarized the characteristics of the present stage, proposed further development measures to make up the disadvantages. Therefore, scholars in our country have certain study on highway industry, but there is only a few research literatures about Shenyang Dalian highway and high-tech industry belt along it. In order to make up for the inadequacy of previous studies, this paper conducts the trend prediction and matching analysis based on the carrying capacity of Shenyang Dalian highway and the development situation of high-tech industry belt in central and southern Liaoning province. 


\section{Analysis on Carrying Capacity of Shenyang Dalian Highway}

Shenyang Dalian highway is the first highway in china, it is also called Shenhai highway in Liaoning section because of its geographical location. So far, the carrying capacity of Shenyang Dalian highway has increased to 80 million each year. The number of passenger capacity is 130 million, it is an important channel in economic development of northeast China. The average width of Shenyang Dalian highway's affected zone is 370 $\mathrm{km}$. It covers six cities including Benxi, Dalian, Shenyang, Liaoyang, Anshan, and Yingkou, it becomes a transportation hub in northeast china and promotes the economic development in the vicinity. Shenyang Dalian highway provides the transportation for Shenyang port and Dalian port. The equipment manufacturing in Shenyang, petrifaction, ship building and high-tech industry in Dalian as well steel industry in Anshan all gather on Shenyang Dalian highway.

The carrying capacity of Shenyang Dalian highway is measured by freight volume of Shenyang Dalian highway, but it is difficult to get freight volume of Shenyang Dalian highway, so we need to statistics freight volume in Liaoning province first, and then calculate the freight volume of Shenyang Dalian highway according to the relationship between input and output. The actual highway freight volume in Liaoning province from 2006 to 2014 can be seen in Table 1.

Table 1. Highway Freight Volume in Liaoning Province from 2006 to 2014

\begin{tabular}{cccccccccc}
\hline Year & 2006 & 2007 & 2008 & 2009 & 2010 & 2011 & 2012 & 2013 & 2014 \\
\hline Freight & 10596 & 11691 & 12134 & 13505 & 15848 & 18498 & 20678 & 20686 & 22213 \\
$\begin{array}{c}\text { Volume(to } \\
\text { ns) }\end{array}$ & 6 & 7 & 6 & 5 & 4 & 2 & 9 & 8 & 8 \\
\hline
\end{tabular}

Source: China statistical yearbook (2006-2014)

Forecasting the highway freight volume in Liaoning province from 2016 to 2020 with trend moving average method, the formula is as followed:

$$
\begin{gathered}
M_{t}^{(1)}=\frac{y_{t}+y_{t-1}+\cdots+y_{t-N+1}}{N} \\
M_{t}^{(2)}=\frac{M_{t}^{(1)}+M_{t-1}^{(1)}+\cdots+M_{t-N+1}^{(1)}}{N} \\
a_{t}=2 M_{t}^{(1)}-M_{t}^{(2)} \\
b_{t}=\frac{2}{N-1}\left(M_{t}^{(1)}-M_{t}^{(2)}\right)
\end{gathered}
$$

Collecting $N=5$, and then get the results are as followed:

$$
M_{2014}{ }^{(1)}=195852.2, M_{2014}{ }^{(2)}=161305.88 \quad \mathrm{a}_{2014}=230398.52 \quad \mathrm{~b}_{2014}=17273.16 \text {, }
$$

finally get the trend moving average model when $t=2014$ :

$$
\hat{y}_{2014+T}=230398.52+17273.16 T
$$

The forecasting results of highway freight volume in Liaoning province from 2016 to 2020 are shown in Table 2.

Table 2. The Forecasting Values of Highway Freight Volume in Liaoning Province from 2016 to 2020

\begin{tabular}{cccccc|}
\hline Year & 2016 & 2017 & 2018 & 2019 & 2020 \\
\hline $\begin{array}{c}\text { Freight } \\
\text { Volume(tons) }\end{array}$ & 264945 & 282218 & 299491 & 316764 & 334037 \\
\hline
\end{tabular}


Note: the data of 2015 have occurred, it is just not in statistical yearbook, so not to forecast.

According to related literature, the ratio between freight volume of Shenyang Dalian highway and Liaoning province is equal to the ratio between GDP of six cities in central and southern Liaoning province and Liaoning province. Using $N_{i}^{\prime}$ to represent freight volume of Shenyang Dalian highway in the $i$ year, and use $N_{i}$ to represent freight volume of Liaoning province in the $i$ year, using $P_{i}$ to represent the ratio between GDP of six cities in central and southern Liaoning province and Liaoning province in the $i$ year. And $N_{i}^{\prime}=P_{i}^{*} N_{i}$.The actual and foresting values of GDP of six cities in central and southern Liaoning province and Liaoning province are shown in Table 3 and Table 4.

Table 3. The Actual GDP Values of Six Cities in Central and Southern Liaoning Province and Liaoning Province from 2006 to 2014

\begin{tabular}{|c|c|c|c|}
\hline Year & $\begin{array}{c}\text { GDP in central and } \\
\text { southern } \\
\text { Liaoning(billion) }\end{array}$ & $\begin{array}{c}\text { GDP in } \\
\text { Liaoning(billion) }\end{array}$ & Ratio $P_{i}$ \\
\hline 2006 & 7476.82 & 9304.52 & 0.8036 \\
\hline 2007 & 9218.11 & 11164.30 & 0.8257 \\
\hline 2008 & 11207.62 & 13668.58 & 0.8200 \\
\hline 2009 & 12452.10 & 15212.49 & 0.8185 \\
\hline 2010 & 14898.96 & 18457.27 & 0.8072 \\
\hline 2011 & 17623.01 & 22226.70 & 0.7929 \\
\hline 2012 & 19528.77 & 24846.43 & 0.7860 \\
\hline 2013 & 21219.37 & 27077.70 & 0.7836 \\
\hline 2014 & 20916.86 & 28626.58 & 0.7307 \\
\hline
\end{tabular}

Source: Liaoning statistical yearbook (2006-2014)

Using trend moving average method to forecast the two groups of data, the results are as followed:

Table 4. The Forecasting GDP Values of Six Cities in Central and Southern Liaoning Province and Liaoning Province from 2016 to 2020

\begin{tabular}{|c|c|c|c|}
\hline Year & $\begin{array}{c}\text { GDP in central and } \\
\text { southern } \\
\text { Liaoning(billion) }\end{array}$ & $\begin{array}{c}\text { GDP in } \\
\text { Liaoning(billion) }\end{array}$ & Ratio $P_{i}$ \\
\hline 2016 & 26410.34 & 34980.55 & 0.7550 \\
\hline 2017 & 28303.57 & 37663.95 & 0.7515 \\
\hline 2018 & 30196.81 & 40347.36 & 0.7484 \\
\hline 2019 & 32090.05 & 43030.76 & 0.7457 \\
\hline 2020 & 33983.28 & 45714.16 & 0.7434 \\
\hline
\end{tabular}

Note: the data of 2015 have occurred, it is just not in statistical yearbook, so not to forecast.

Then the freight volume of Shenyang Dalian highway from 2006 to 2020 is shown in Table 5 . 
Table 5. The Freight Volume of Shenyang Dalian Highway from 2006 to 2020

\begin{tabular}{|c|c|c|}
\hline Year & Freight Volume(tons) & \\
\hline 2006 & 85151 & \\
\hline 2007 & 96536 & \multirow{3}{*}{ Actual } \\
\hline 2008 & 99498 & \multirow{5}{*}{ Values } \\
\hline 2009 & 110549 & \\
\hline 2010 & 127930 & \\
\hline 2011 & 146668 & \multirow{3}{*}{ Forecasting } \\
\hline 2012 & 162532 & \multirow{2}{*}{ Values } \\
\hline 2013 & 162112 & \\
\hline 2014 & 162312 & \\
\hline 2016 & 200034 & \\
\hline 2017 & 212080 & \\
\hline 2018 & 224145 & \\
\hline 2019 & 236226 & \\
\hline 2020 & 248319 &
\end{tabular}

Note: the data of 2015 have occurred, it is just not in statistical yearbook, so not to forecast.

\section{Analysis on Development Condition of High-Tech Industry Belt in Central and Southern Liaoning Province}

\subsection{Development Situation of High-Tech Industry Belt in Central and Southern Liaoning Province}

From the concept of space form, with the influences from "two point one axis" to the lower axis and point, six national high-tech industrial development zones have formed along Shenyang Dalian highway, they are Shenyang, Dalian, Anshan, Liaoyang, Yingkou and Benxi. Shenyang and Dalian are the attraction and diffusion points in the High-tech industry belt, Anshan, Liaoyang, Yingkou and Benxi are the lower points along main line of Shenyang Dalian highway in the High-tech industry belt, the economy of these national high-tech industrial development zones are increasing depending on the advantages of the traffic , and gradually spread and permeate its influence, finally form High-tech industry in central and southern Liaoning province which gathers various kinds of elements.

Shenyang and Dalian national high-tech industrial development zones are the main force in the development of the central and southern Liaoning province. Shenyang high-tech industrial zone covers 32 square kilometers, its total construction layout is "one city and three gardens", it mainly supports the development of new materials, biological engineering and so on, so it becomes high-tech industry development base of a high level in Liaoning province. Dalian high-tech industrial zone covers 153 square kilometers, the location is the community of universities and research institutions in Dalian, and provides support from human, intelligence and technology, there are many high-tech fields such as software, information service, integrated circuits, biological medicine and digital manufacturing there. In recent years, the innovation advantages of Dalian high-tech industrial development zone become more apparent, characteristic industry develops rapidly, and industrial structure get a further optimization upgrading.

As the node for the main line of Shenyang Dalian highway, Anshan high-tech industrial development zone mainly concentrate on the construction and development of laser industrial zone, and obtained ideal results, achieved a high starting point in the industry; Liaoyang high-tech industrial development zone has the biggest chemical fiber joint 
enterprises in northeast China, it has become a new pattern with the main body of chemical fiber and common development of electronic information and new building materials industries; Yingkou high-tech industrial development zone assembles the metallurgical, petrochemical and equipment manufacturing industries, the phenomenon of high-tech industry cluster appeared preliminarily; Benxi high-tech industrial development zone includes many well-known enterprises, these enterprises focus their main force on biological pharmaceutical industry, it formed a complete industrial chain of biomedicine, and gradually achieve the goals of industry clustering development. In future, the department of science in Benxi proposed five measures to promote the large-scale construction of the medicine city.

\subsection{Prediction on Development Trend of High-Tech Industry Belt in the Central and Southern Liaoning Province}

High-tech industry belt in central and southern Liaoning province nearly carries the most production activities in Liaoning province, so we use high-tech industry output values to measure the industry size of high-tech industry belt in central and southern Liaoning province, and then using trend moving average method to get the forecasting values of high-tech industry belt from 2016 to 2020in the central and southern Liaoning province, the result is shown in Table 6.

\section{Table 6. The Production Values of High-Tech Industry Belt from 2006 to 2020 in the Central and Southern Liaoning Province}

\begin{tabular}{|c|c|c|}
\hline Year & Production Values (billion) & \\
\hline 2006 & 753.00 & \multirow{4}{*}{ Actual } \\
\hline 2007 & 1019.00 & \multirow{2}{*}{ values } \\
\hline 2008 & 1177.00 & \\
\hline 2009 & 1314.00 & \\
\hline 2010 & 1712.00 & \\
\hline 2011 & 1898.00 & \multirow{3}{*}{ Forecasting } \\
\hline 2012 & 2214.00 & \multirow{2}{*}{ values } \\
\hline 2013 & 2362.40 & \\
\hline 2014 & 2681.83 & \\
\hline 2016 & 3178.65 & \\
\hline 2017 & 3429.90 & \\
\hline 2018 & 3681.15 & \\
\hline 2019 & 3932.40 &
\end{tabular}

Source: China high-tech industry data (2006-2014)

Note: the data of 2014 is forecasting value.

\subsection{Analysis on the Relationship Between the Carrying Capacity of Shenyang Dalian Highway and the Development of High-Tech Industry Belt in Central and Southern Liaoning Province}

The high-tech industry belt is different from traditional industry belt, it is greatly influenced by layout factor, its demand for the development environment is higher, the development of high-tech industry belt has certain requirements on the carrying capacity of highway along it. The relationship between the carrying capacity of Shenyang Dalian highway and development of high-tech industry belt in central and southern Liaoning province are as followed: 
(1) The carrying capacity of Shenyang Dalian highway is more than the freight demand for the development of high-tech industry belt in central and southern Liaoning province, if that happens, it will cause waste of logistics resources and lead to the increased cost of logistics.

(2) The carrying capacity of Shenyang Dalian highway is less than the freight demand for the development of high-tech industry belt in central and southern Liaoning province, if that happens, it will affect the scale of high-tech industrial belt.

(3) The carrying capacity of Shenyang Dalian highway is equal to the freight demand for the development of high-tech industry belt in central and southern Liaoning province, this is the optimal situation, if the capacity of Shenyang Dalian highway and the transportation demand for the development of high-tech industry belt achieve the best match, it can effectively use logistics resources to develop high-tech industry belt better, and promote the development of economy.

\section{Matching Analysis on Carrying Capacity of Shenyang Dalian Highway and High-Tech Industry Belt in Central and Southern Liaoning Province}

According to the production values of the central and southern in Liaoning province and the freight volume of Shenyang Dalian highway, we conduct scatter diagram which is shown in Figure 1.

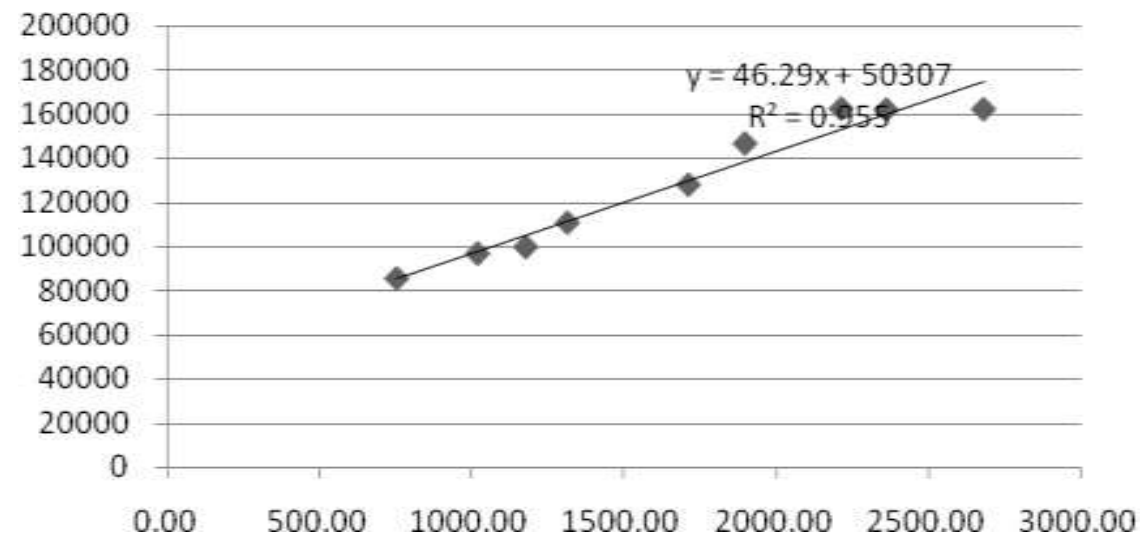

\section{Figure 1. The Linear Relationship Between the Industry Size of High-Tech Industry Belt in Central and Southern Liaoning Province and Carrying Capacity of the Shenyang Dalian Highway}

According to the Figure 1, we can know there is linear growth relationship between the industry scale of high-tech industry belt in central and southern Liaoning province and carrying capacity of the Shenyang Dalian highway, so the simple linear regression model is established as followed:

$$
y=k x+b
$$

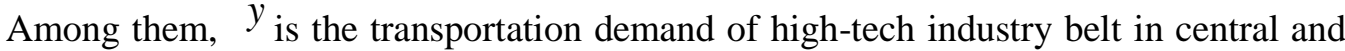
southern Liaoning province, $x$ is the production values of the Shenyang Dalian highway.

Estimating and testing the parameters, the unary linear regression equation is obtained as followed:

$$
y=46.29 x+50307.12
$$

$R^{2}=0.955$, the fitting effect is very good, under the significant level $\alpha=0.05, F=148.4644$, Sig $=0.000$,the actual significant level of value $F$ is value $P$,because $P<\alpha$, we reject the null hypothesis, the significance of original 
equation is high. Under the significant level $\alpha=0.05$, the values of $t$ testing are 7.4 and 12.1. the actual significant level of value ${ }^{t}$ is value $P, \operatorname{Sig}$ are 0 and 0 , because $P<\alpha$, the significance of the variables is high, the model represents that the industry size of high-tech industry belt in central and southern Liaoning province effects significantly the freight volume of Shenyang Dalian highway, therefore, the development of high-tech industry belt in central and southern Liaoning province demand for the freight volume of Shenyang Dalian highway. So model (7) can be typed as demand forecasting model for the development of high-tech industry belt in central and southern Liaoning province, to calculate the transportation demand, put respectively the production values of high-tech industry belt in central and southern Liaoning province into the formula to get the transportation demand, the results are shown in Table 8.

\section{Table 7. The Freight Demand of High-Tech Industry Belt in Central and Southern Liaoning province from 2016 to 2020}

\begin{tabular}{cccccc} 
Year & 2016 & 2017 & 2018 & 2019 & 2020 \\
\hline $\begin{array}{c}\text { Freight } \\
\text { Demand(tons) }\end{array}$ & 197447 & 209077 & 220707 & 232338 & 243968 \\
\hline
\end{tabular}

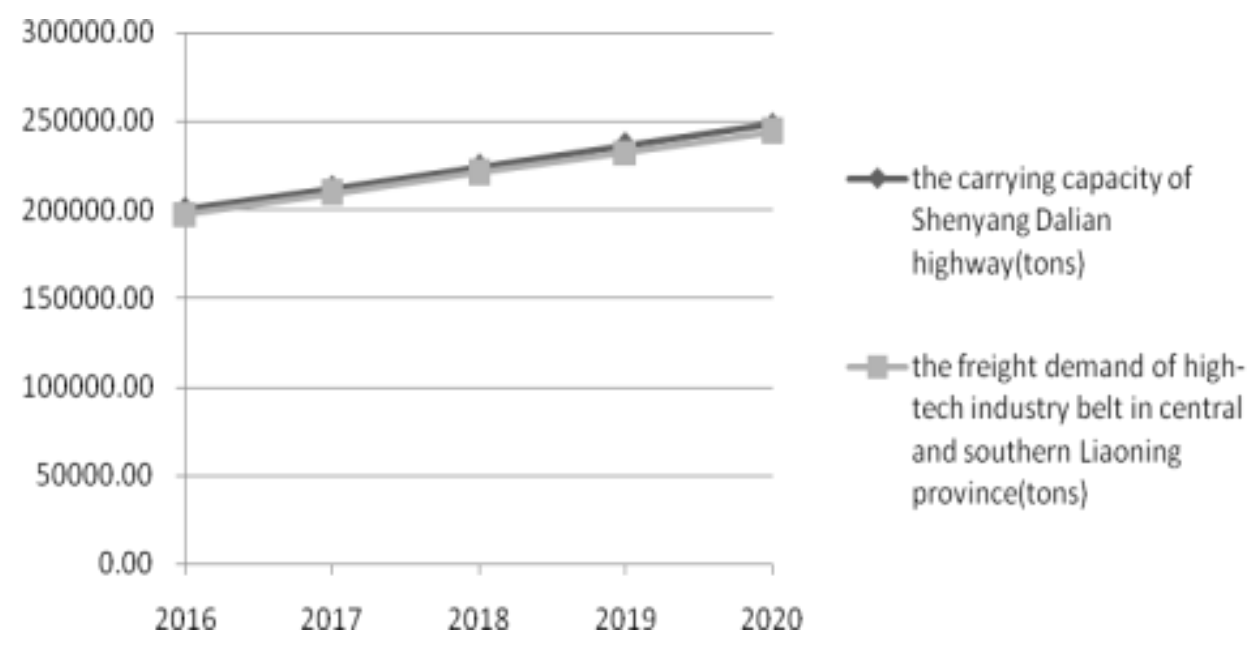

Figure 2. Contrast between the Carrying Capacity of Shenyang Dalian Highway and the Freight demand of High-Tech Industry Belt in Central and Southern Liaoning Province

In conclusion, the carrying capacity of Shenyang Dalian highway is more than the freight demand for the development of high-tech industry belt in central and southern Liaoning province, which doesn't reach the best match, so we should focus on the development of high-tech industry belt in central and southern Liaoning province in order not to waste the logistics resources.

\section{Suggestions}

Compared with the carrying capacity of Shenyang Dalian highway, the development scale of high-tech industry belt in central and southern Liaoning province is not enough, in order to promote the development of industry, the measures are as followed:

(1) Conducting secondary development depending on "two point one axis" to promote the balanced development of high-tech industry belt in central and southern Liaoning province. At present, the production values of high-tech industry in Shenyang and Dalian 
are more than the rest four cities, the regional development is unbalanced, so we should develop the advantaged industries of the rest four cities, for example, Liaoyang should consider aromatics and fine chemicals industry and industrial aluminum profile industry as the key points. Benxi should focus on medicines scale construction.

(2) Improving the personnel training and absorbing mechanism to promote high-tech talents gathering in central and southern Liaoning province. The shortage of human resources management system leads to the loss of high-tech talents in central and southern Liaoning province, the development of high-tech industry needs innovation, and innovation needs talents. So Liaoning province should take special mechanism and policy to build "talent highland", strengthen the cooperation between the company, school and research institutes, also encourage scientific research personnel to start a company or become a member of the company with personal stake, and improve the salary, benefits and promotion systems to promote the gathering of high-tech talents.

(3) Improving the development policy of the high-tech industry in central and southern Liaoning province. In order to promote the transformation and upgrade of the national and provincial high- tech industries, and further promote the development of the high-tech zones, in 2013, the provincial government issued opinions on accelerating the development of high-tech industrial development zones. In 2014, it formulated implementation plan on speeding up the transformation and upgrading of the whole province high-tech zones. In 2015, it tried out the policy of scientific and technological innovation vouchers, however Liaoning province still needs to publish certain policy on taxes and land requisition corresponding.

\section{Acknowledgments}

The paper is fund project: Research on the development strategy of Shenyang Dalian High-tech Industry Belt Project funded by Liaoning province science and technology plan (2013401028)

\section{References}

[1] W. Dong Hao, "Highway industry area evaluation theory and method", China soft science, vol. 1, (1997), pp. 104-107.

[2] L. Haidong, "Study on the highway industry area", Productivity research, vol. 10, (2004), pp. 113-115, 128.

[3] N. Jun., "highway industry area partition method comparison research", Value engineering, vol. 33, (2012), pp. 82-84.

[4] Z. Chunhong, "linking the economic belt of Liaoning highway transport high-speed economy of central", Journal of China highway, vol. 3, (2004), pp. 42-45.

[5] Y. Feng and Z. Wenjuan, "Linking the scope and characteristics of economic belt analysis", Journal of commercial age, vol. 3, (2010), pp. 128-129.

[6] Z. Ren, "Liaoning province high and new technology industry development research", China, vol. 4, (2015), pp. 33-34. 